Check for updates

Cite this: RSC Adv., 2018, 8, 11498

Received 30th November 2017 Accepted 28th February 2018

DOI: 10.1039/c7ra12556a

rsc.li/rsc-advances

\section{A synthesis and performance evaluation of a highly efficient ecological dust depressor based on the sodium lignosulfonate-acrylic acid graft copolymer}

\author{
Yanghao Liu, (D) ${ }^{a}$ Wen Nie, ${ }^{\star a b}$ Yubing Mu, ${ }^{a}$ Haihan Zhang, ${ }^{a}$ Hongkun Wang, ${ }^{a} \mathrm{Hu} \mathrm{Jin}^{\mathrm{a}}$ \\ and Zhiqiang Liu (iD) ${ }^{a}$
}

In this paper, a highly efficient and environmentally-friendly dust depressor was developed based on the sodium lignosulfonate-acrylic acid graft copolymer. Using the grafting ratio as an index, a three-factor and four-level orthogonal experiment was conducted to optimize the fabrication conditions of the graft copolymer. At a reaction temperature of $60{ }^{\circ} \mathrm{C}$, feed ratio $m_{\mathrm{SLS}-\mathrm{AA}}$ of $1: 3$, and $\mathrm{FeSO}_{4} \cdot 7 \mathrm{H}_{2} \mathrm{O}$ content of $2.5 \%$, the prototype produced the highest grafting ratio. The microstructure of the graft copolymer was measured using Fourier transform infrared spectrometry (FTIR) and nuclear magnetic resonance $\left({ }^{1} \mathrm{H}\right.$ NMR). Furthermore, the influence of glycerol and the JFC penetrant on the contact angle between the compound solution and coal powder was investigated. Finally, four formulas of dust depressor were selected based on the experimental results. The dust-control performance of the four dust depressors was then tested on a large-scale spray dust suppression simulation platform. The results show that after applying formula 1 at various distances from the spray field, the average dust reduction rates of the total dust (respirable dust) at each point increased. Compared to the water-spraying dust suppression technique, the dust concentration is significantly reduced after the graft copolymer dust depressor is applied.

\section{Introduction}

In recent years, there has been an ever-increasing environmental issue in industrial working areas, due to pollutants that consist mainly of inhalable particles (PM10) and fine particles (PM2.5). In the coal industry in particular, most of the respirable dust can enter directly into a human's lungs and form deposits there; furthermore they can gain access to the circulation system, causing severe hazards for the human body. ${ }^{1-3}$ Among the current dust suppression methods, spraying, using water as the liquid, has been applied extensively in underground coalmines. However, the coal dust's surface contains a large amount of the hydrophobic nonpolar group, leading to a strong hydrophobicity of the coal dust. ${ }^{4}$ Moreover, water's large surface tension leads to poor wettability with regard to the coal dust..$^{5-7}$ Thus, most of the coal dust, particularly the respirable dust, does not become wet quickly and efficiently and is therefore not suppressed by water. Due to their small size, some of the dust particles deposited on

${ }^{a}$ College of Mining and Safety Engineering, Shandong University of Science and Technology, Qingdao 266590, Shandong Province, China. E-mail: niewen@sdust. edu.cn; liuyanghao2012@163.com

${ }^{b}$ State Key Laboratory of Mining Disaster Prevention and Control Co-found by Shandong Province and the Ministry of Science and Technology, Shandong University of Science and Technology, Qingdao 266590, China the ground can also be dissipated easily by the wind, leading to secondary dust emissions. However, adding a dust depressor to water has proved to be an effective way of increasing the dust suppression rate by spraying. The development of a highly efficient dust depressor based on the dust's properties is therefore of great importance with regard to improving the dust control performance. To date, researchers worldwide have paid a great deal of attention to the development of a chemical dust depressor and there have been some notable achievements. For example, Kim J. et al. ${ }^{8}$ fabricated a dust depressor for wetting coal dust using a nonionic surfactant including surfynol 440, macol 30, plurafac RA 43, mindust 293, and neodol 92 as the main contents. Furthermore, Haining Wang et al. ${ }^{9}$ developed a dust binder from a starch grafted sodium polyacrylate. Cuifeng $\mathrm{Du}$ et al. ${ }^{10}$ synthesized a cohesive dust suppressant using a polymer film forming agent, polysaccharide polymer filler, and other auxiliaries. Miguel. A. Medeirosa et al. ${ }^{11}$ studied the dust suppressant fabricated from a glycerol polymerization and catalyzed by acids (sulfuric acid or phosphoric acid) and bases. Finally, Shuyan Cheng et al. ${ }^{12}$ created an environment-friendly dust depressor using byproducts from the production of biodiesel, such as glycerin.

The main contents of the chemical dust depressors that emerged from the literature between 2001 and 2009 are shown 
in Fig. $1 .^{13,14}$ As can be seen from this figure, the components of the chemical dust depressor have evolved from simple surfactants, along with their compounds and inorganic salts, to organic polymers. There is also an increasing tendency to use green, environmentally-friendly dust depressors. Therefore, combining the characteristics of organic polymers and environmentally-friendly dust depressors can promote their wider usage as a novel and highly efficient dust depressor.

As a byproduct from the papermaking industry, sodium lignosulfonate (LSL) benefits from its low cost, with an annual production of approximately 150000 tons in China. ${ }^{15,16}$ Lignin is a renewable resource with good water solubility and cohesion, nontoxicity, and biodegradability. The active groups in SLS molecules such as hydroxyl and the sulfonic group can bond with coal particles and form a solidified layer on the coal's surface. After forming a sodium lignosulfonate-acrylic acid graft copolymer $\left(\mathrm{GC}_{\mathrm{S}-\mathrm{A}}\right)$ with acrylic acid (AA), the surface tension is significantly reduced. In addition, AA has the structure of $\mathrm{CH}_{2}=\mathrm{CH}-\mathrm{COOH}$, where the carboxylic acid with a double bond is introduced to $\mathrm{GC}_{\mathrm{S}-\mathrm{A}}$. The carboxylic acid in a $\mathrm{GC}_{\mathrm{S}-\mathrm{A}}$ molecule provides a crosslinking point for the reaction. Moreover, the crosslinking structure formed from the reaction between carboxyl and hydroxyl in the molecule chain or SLS can greatly enhance the viscosity of the copolymer. ${ }^{17-19}$ Therefore, the inclusion of SLS in a chemical dust depressor has a number of advantages.

The graft copolymer of SLS and AA consists of two polymerization processes: the polymerization of AA grafting to SLS and the self-polymerization of $\mathrm{AA}^{\mathbf{2 0 , 2 1}}$ The self-polymerization of AA is a simple process, and the reaction equation is shown in eqn (1):

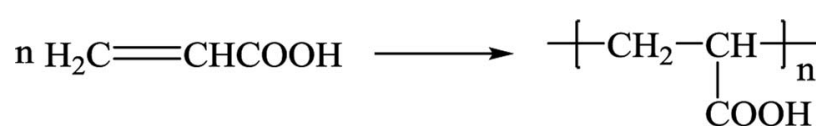

(1)

The graft polymerization of AA and SLS can take place at C-5 or in phenolic groups. As shown in eqn (2), SLS has a dynamic equilibrium. The graft polymerization of SLS and AA can occur in the following two pathways: (1) AA grafting to SLS following

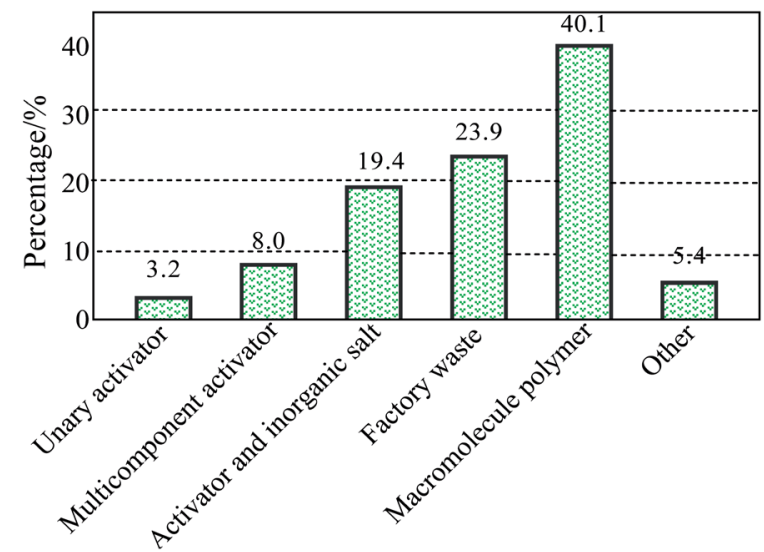

Fig. 1 Statistics of various dust depressors from 2001 to 2009. a one-by-one sequence, as shown in eqn (3); and (2) AA grafting to SLS after its self-polymerization, as shown in eqn (4).

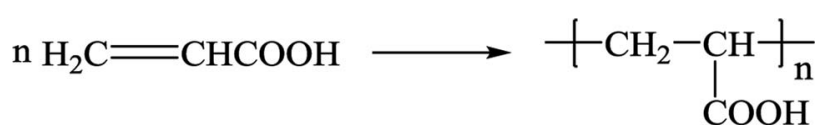

$$
\begin{gathered}
\mathrm{LS}^{\bullet}+\mathrm{M} \rightarrow \mathrm{LS}-\mathrm{M}^{\bullet}+(n-1) \mathrm{M} \rightarrow \mathrm{LS}-\mathrm{Mn} \\
n \mathrm{M} \rightarrow \mathrm{Mn}^{\bullet}+\mathrm{LS} \rightarrow \mathrm{LS}-\mathrm{Mn}
\end{gathered}
$$

Glycerin is a nontoxic, noncorrosive, and nonflammable liquid with a good moisture absorption capability, which satisfies the requirements of an ideal green solvent. The utilization of glycerin has recently become a focus of environmentally-focused chemistry. Previously, most of the studies in this area concentrated on the conversion of glycerin, while little has been explored with regard to utilizing it in new ways. ${ }^{22}$ It has been reported that glycerin can act as an auxiliary to increase the crosslinking degree among the large molecule chains of the graft copolymer, and expand the threedimensional water-absorption space by forming a network structure. ${ }^{23,24}$ Therefore, in this paper, based on $\mathrm{GS}_{\mathrm{S}-\mathrm{A}}$, a new type of highly efficient and environmentally-friendly dust depressor is synthesized using glycerin as a wetting agent and the JFC penetrant as excipients.

\section{Experimental methods}

\section{Raw materials and equipment}

Sodium lignosulfonate (SLS, industrial grade), acrylic acid (AA, analytical purity), $\mathrm{FeSO}_{4} \cdot 7 \mathrm{H}_{2} \mathrm{O}$, acetone, glycerin, JFC penetrant, distilled water, magnetic stirrer with constant temperature and heater (85-1), water recycling vacuum pump (8HZD(III)), vacuum drying oven (DHG-9030), automatic tensionmeter (JK99C), nuclear magnetic resonance spectrometer (Bruker, AVANCE III 400, Swiss), FTIR spectrometer (Nicolet 6700), spin viscometer (NDJ-79).

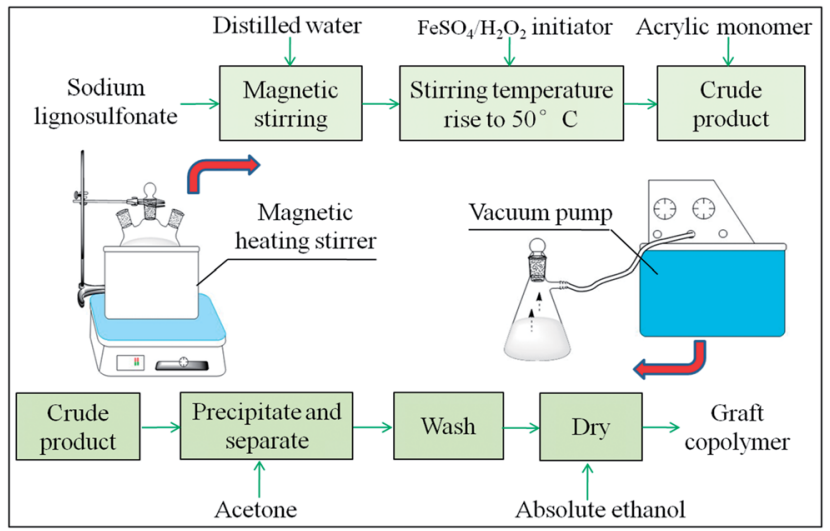

Fig. 2 The reaction process of the SLS-AA graft copolymer. 


\section{A synthesis of the graft copolymer}

The SLS solution and distilled water of a certain ratio were added to a three-neck flask $(250 \mathrm{~mL})$. After stirring for $10 \mathrm{~min}$ with a magnetic stirrer to activate the reactant, an initiator and AA were added to the solution. The reaction temperature was maintained at 50 to $80{ }^{\circ} \mathrm{C}$, and the raw copolymer was obtained after 3 hours. The reaction process of the copolymer is shown in Fig. 2. After separation and purification, the product was weighed, and the $\mathrm{GC}_{\mathrm{S}-\mathrm{A}}$ yield was calculated following the process in ref. 25 . The calculation equation is as follows: ${ }^{26}$

$$
G=\frac{W_{\mathrm{GC}}}{W_{\mathrm{SLS}}+W_{\mathrm{AA}}} \times 100 \%
$$

where $G$ is the yield (\%), $W_{\mathrm{GC}}$ is the mass (g) of $\mathrm{GC}_{\mathrm{S}-\mathrm{A}}, W_{\mathrm{SLS}}$ is the mass $(\mathrm{g})$ of SLS, and $W_{\mathrm{AA}}$ is the mass (g) of glycerin.

\section{The design of the individual experiment}

The surface tension of the SLS solution. An automatic tensionmeter (JK99C) was employed to measure the surface tension of the SLS solution. The tensionmeter has a measurement range of $(0-1.8) \times 10^{3} \mathrm{~N} \mathrm{~cm}^{-1}$ and an accuracy of $10^{-6} \mathrm{~N} \mathrm{~cm}^{-1}$. The surface tension of the SLS and $\mathrm{GC}_{\mathrm{S}-\mathrm{A}}$ solution with various mass concentrations was then measured. The optimized concentration range was determined after comparing the surface tension before and after the modification of the SLS. Each solution was measured three times, and the average value was used to ensure the accuracy of the results.

The viscosity of the $\mathbf{G C}_{\mathbf{S}-\mathbf{A}}$ solution. The cohesive force among the dust particles relies on the viscosity of the dust depressor. Thus, the viscosity is an important parameter for determining the dust depressor's practical application. ${ }^{27}$ In this paper, a spin viscometer (NDJ-79) was used to measure the viscosity of the $\mathrm{GC}_{\mathrm{S}-\mathrm{A}}$ solution with various mass concentrations. The \#1 spinner was adopted with a rotation speed of $60 \mathrm{rpm}$. Each experiment was repeated three times to obtain the average value.

The water retention of coal dust with glycerin. As an auxiliary, glycerin can enhance the crosslinking degree among the large molecules of the graft copolymer, and increase the threedimensional water-absorption space by forming a network structure. However, if overdosed, the stretching of the molecule chain can be limited, making it difficult to expand. In order to obtain the best concentration range, a water retention experiment was designed to test the water-holding capacity of coal powders, with various coalification degrees, under the presence of glycerin at various concentrations.

Six types of coal sample were selected based on the coalification degree: lignite coal (HM, Shenum, Shanxi, China), long flame coal (CY, Hebi, Henan, China), 1/3 coking coal (1/3JM, Huipodi, Shanxi, China), fat coal (FM, Jiangzhuang, Shandong, China), lean coal (PSM, Shiquan, Shanxi, China), and anthracite coal (WY, Tongzi, Guizhou, China). Each coal sample was collected according to the published national standard (GB/T482-2008) to ensure its representativeness. ${ }^{28}$ After being grinded to a coal powder by a vibrationgrinding machine, the samples were put through a 200 mesh standard sieve, labeled, and stored at a low temperature.
The water retention test evaluates mainly the water-holding capacity of the solution, based on the variation trend of the water loss rate with time. The water loss rate can be calculated as follows:

$$
\eta=\frac{m_{0}-m_{i}}{m} \times 100 \%
$$

where $\eta$ is the water loss rate (\%), $m_{0}$ is the initial mass (g) of the Petri dish, $m_{i}$ is the mass ( $\mathrm{g}$ ) of the Petri dish after $i$ hours, and $m$ is the mass $(\mathrm{g})$ of the $10 \mathrm{~mL}$ solution.

$20 \mathrm{mg}$ of each coal sample was placed in a $60 \mathrm{~mm}$ Petri dish, and $10 \mathrm{~mL}$ of glycerin at different mass concentrations was sprayed uniformly onto the dust sample. As a control experiment, water was also sprayed onto separate samples. Next, the samples were placed in a drying oven at $70{ }^{\circ} \mathrm{C}$, with the Petri dish's mass measured hourly for 7 hours. The water loss rate was then calculated.

The individual permeability measurement. After pretreatment (a 200 mesh sieve, dried at $105{ }^{\circ} \mathrm{C}$, cool down), two parts of $15 \mathrm{~g}$ of coal dust were placed in individual $10 \mathrm{~mm} \times$ $10 \mathrm{~mm}$ test tubes. The test tubes were vibrated until the dust filled $7.5 \mathrm{~cm}$ of the tubes. $24 \mathrm{~mL}$ of the JFC penetrant and distilled water were dropped slowly into the test tubes with burettes. The penetration depth of the solution as a function of time was recorded.

The orthogonal experiment. The concentration ranges obtained from each individual experiment were used to design an orthogonal experiment for selecting the optimized formula of the dust depressor. A three-factor and four-level orthogonal experiment was performed using a $\mathrm{GC}_{\mathrm{S}-\mathrm{A}}$ solution, glycerin, and the JFC penetrant as the three factors (noted as A, B, and C). A max-min difference analysis was conducted on the experimental value of the contact angle from each sample.

An optical droplet morphology analyzer (DSA100) was adopted to measure the dynamic contact angle between different solutions and the fat coal from Jiangzhuang. The contact angle between the coal and solution at $30 \mathrm{~s}$ was measured, and the experiment was repeated four times to obtain the average value for each solution.

\section{The chemical structure of the dust depressor}

The nuclear magnetic resonance measurement. A nuclear magnetic resonance spectrometer (Bruker, AVANCE III 400 $\mathrm{MHz}$, Swiss) was employed, which used TMS as an internal marker and deuterated water as a solvent. The hydrogen nuclear magnetic resonance spectra of the SLS and $\mathrm{GC}_{\mathrm{S}-\mathrm{A}}$ samples were measured.

The FTIR measurement. An FTIR spectrometer (Nicolet 6700) was used in this experiment. After dried in vacuum, the product was mixed with $\mathrm{KBr}$ at a ratio of $1: 150$. The FTIR spectrum of the mixed powder was then measured in the range of 4000 to $400 \mathrm{~cm}^{-1}$ with five scan times..$^{29,30}$

The spray dust suppression simulation test. The spray dust suppression simulation test was conducted on a large-scale mine spray simulation platform in the key state laboratories at the School of Mines, Shandong University of Science and Technology. The spray simulation setup consists of 
(a)
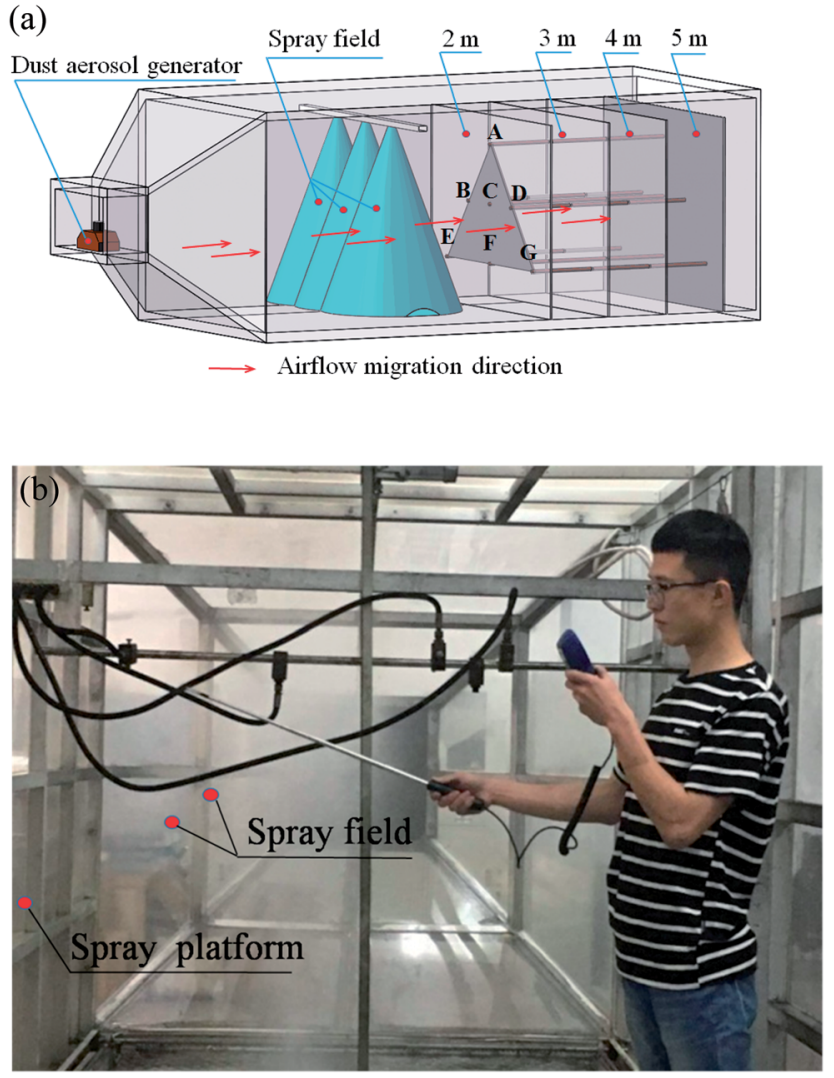

Fig. 3 The spray dust suppression experiment: (a) the distribution of the measurement points and cross sections in the large-scale spray test box; (b) the field measurement of spray dust concentration.

a rectangular test box of $6 \mathrm{~m} \times 3 \mathrm{~m} \times 2.5 \mathrm{~m}$, a spray booster pump, water tanks, spray pipes, and high-pressure gauges. The spray nozzle was a single water swirl nozzle often used in coalmines. The atomizing form was an $\mathrm{X}$ shape diversion core flaring fitting with diameter of $2.4 \mathrm{~mm}$. The spray pressure was set to $8 \mathrm{MPa}$, according to the general spray pressure used in China's coal mining equipment. In the simulation, the dust was emitted by a coal dust aerosol generator. To monitor the dust mass concentration accurately, cross sections at $2,3,4$, and $5 \mathrm{~m}$ from the spray field were selected with 7 measurement points in each cross section, labeled A to G. The dust concentration was measured by a dust sampler for mines (AKFC-92A). Fig. 3(a) shows the three-dimensional distribution of the measurement points and cross sections in the test box. Fig. 3(b) shows a photo of the field dust concentration measurement.

Scanning electron microscope (SEM) experiment. The present experiment employs Nova Nano SEM 450 HighResolution SEM to conduct observation over the surface morphology of two types of coal powder, i.e., the dry coal powder without receiving dust suppressant treatment, and the coal powder with hardened film formed on the surface with the present hybrid dust suppressant applied. Before the experiment starts, the dry coal powder is sprayed with the dust suppressant, and placed in a drying chamber for desiccation such that a hardened film is formed on the sample surface. The resulting sample is then fixed to a sample holder with double-sided tape, which is in turn placed in a SEM sample chamber. After the vacuum is applied to the chamber, SEM images are taken.

The influence of dust suppression on the quality of coal. According to the coalification degree of the samples, four typical coal samples were selected. An automatic industrial analyzer (WS-G818), automatic sulfur meter (WS-S501), and automatic calorimeter (WS-C800) were used to measure the water content, dust content, volatile content, sulfur content, and calorific value of the coal powders before and after spraying the new compound dust depressor. In addition, the effect of the dust depressor on the quality of the coal was analyzed. Fig. 4 shows a photo of the automatic sulfur meter (WS-S501).

\section{Results and discussion}

\section{The optimization of the graft copolymerization}

In order to determine the optimum reaction conditions, based on the effect of various factors, the mass fraction and reaction time in this experiment were set as constant, and a three-factor and four-level orthogonal experiment was conducted to obtain the optimal experimental conditions. Here $A$ denotes the reaction temperature $\left({ }^{\circ} \mathrm{C}\right), B$ denotes the mass fraction of acrylic acid and sodium lignosulfonate, and $C$ denotes the mass fraction (\%) of $\mathrm{FeSO}_{4} \cdot 7 \mathrm{H}_{2} \mathrm{O}$. The experimental variable is the yield of the graft copolymer $G$, and the optimized condition has the largest $G$. The levels of the various factors in the orthogonal experiment are shown in Table 1, and the results are shown in Table 2.

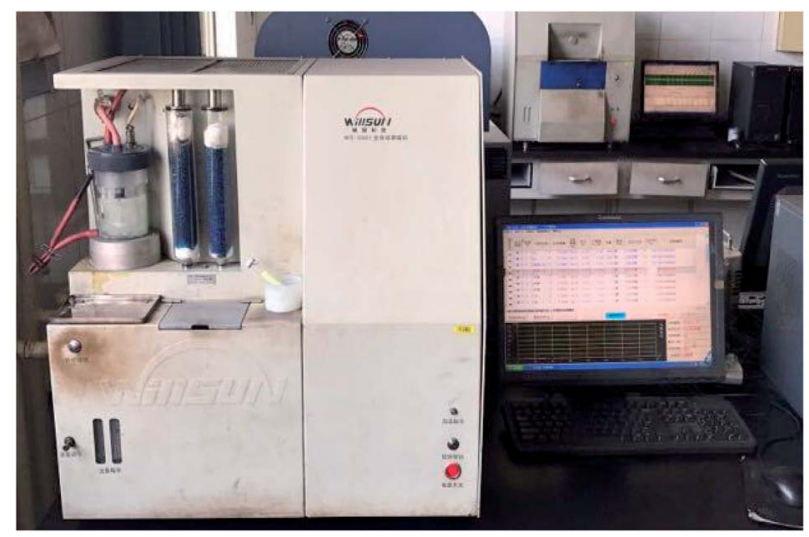

Fig. 4 The automatic sulfur meter (WS-S501).

Table 1 The levels of the various factors in the orthogonal experiment

\begin{tabular}{llll}
\hline & \multicolumn{2}{l}{ Factor } & \\
\cline { 2 - 4 } Level & $A\left({ }^{\circ} \mathrm{C}\right)$ & $B$ & $C(\%)$ \\
\hline 1 & 50 & $1: 2$ & 2.5 \\
2 & 60 & $1: 3$ & 3 \\
3 & 70 & $1: 3.5$ & 3.5 \\
4 & 80 & $1: 4$ & 4
\end{tabular}


Table 2 The results of the orthogonal experiment

\begin{tabular}{lllll}
\hline No. & $A\left({ }^{\circ} \mathrm{C}\right)$ & $B$ & $C(\%)$ & $G(\%)$ \\
\hline 1 & 50 & $1: 2$ & 2.5 & 69.6 \\
2 & 50 & $1: 3$ & 3 & 68.4 \\
3 & 50 & $1: 3.5$ & 3.5 & 58.1 \\
4 & 50 & $1: 4$ & 4 & 62.9 \\
5 & 60 & $1: 2$ & 3 & 55.7 \\
6 & 60 & $1: 3$ & 2.5 & 66.2 \\
7 & 60 & $1: 3.5$ & 4 & 71.7 \\
8 & 60 & $1: 4$ & 3.5 & 78.3 \\
9 & 70 & $1: 2$ & 3.5 & 42.3 \\
10 & 70 & $1: 3$ & 4 & 58.2 \\
11 & 70 & $1: 3.5$ & 2.5 & 74.1 \\
12 & 70 & $1: 4$ & 3 & 45.3 \\
13 & 80 & $1: 2$ & 4 & 54.6 \\
14 & 80 & $1: 3$ & 3.5 & 52.9 \\
15 & 80 & $1: 3.5$ & 3 & 76.8 \\
16 & 80 & $1: 4$ & 2.5 & 67.5 \\
\hline $\mathrm{K}_{1}$ & 64.75 & 55.55 & 69.35 & \\
$\mathrm{~K}_{2}$ & 67.98 & 71.38 & 61.55 & \\
$\mathrm{~K}_{3}$ & 54.98 & 70.18 & 57.9 & $A_{2} B_{2} C_{1}$ \\
$\mathrm{~K}_{4}$ & 62.95 & 63.5 & 61.85 & \\
$\mathrm{R}$ & 13 & 15.83 & 11.45 & \\
\hline
\end{tabular}

According to Table 2, the max-min difference analysis of the orthogonal experiment results shows that the main factor affecting the yield of the graft copolymer is the level of AA. A low AA level leads to its low concentration near the SLS molecules, and part of the SLS free radicals lose activity before the grafting reaction, resulting in a decreased yield. However, if the AA level is overly high, an AA self-polymerization reaction can occur, reducing the yield of the graft polymerization reaction between AA and SLS. As shown in Table $2, A_{2}, B_{2}$, and $C_{1}$ correspond to the highest graft yield. Thus, the optimized combination from the orthogonal experiment is $A_{2} B_{2} C_{1}$. The effect of the three factors on the copolymer yield ranks as: $C>A>B$.

\section{The IR analysis of the graft copolymer}

Fig. 5 show the FTIR spectra of the SLS before and after the graft reaction. The comparison between the two figures shows that

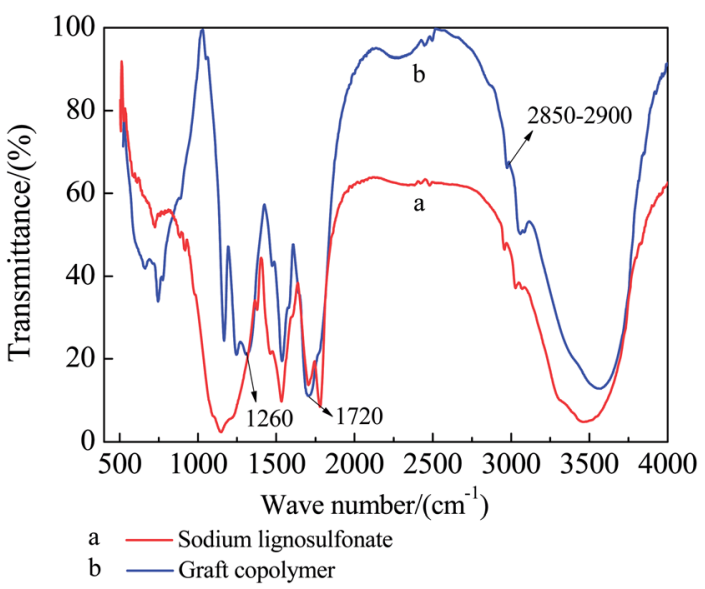

Fig. 5 The FTIR of SLS and $\mathrm{GC}_{\mathrm{S}-\mathrm{A}}$.

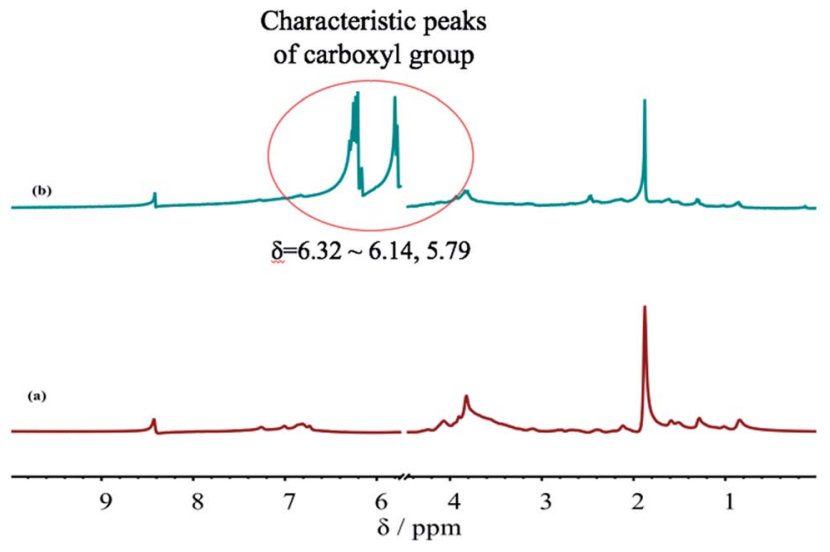

Fig. 6 The ${ }^{1} \mathrm{H}$-NMR spectra of the SLS before and after grafting with the AA: (a) SLS; (b) $G_{S-A}$.

the grafted $\mathrm{GC}_{\mathrm{S}-\mathrm{A}}$ exhibits apparent hydroxyl absorption peak at $1720 \mathrm{~cm}^{-1}$, and the $\mathrm{C}-\mathrm{O}$ stretching vibration peak at $1260 \mathrm{~cm}^{-1}$ is significantly enhanced, due to the carboxyl introduced to SLS after grafting AA. All the other features of the two spectra show no apparent difference, indicating that AA is grafted to SLS and forms graft copolymer.

\section{An analysis of ${ }^{1} \mathrm{H}-\mathrm{NMR}$ spectrum}

Fig. 6 shows the ${ }^{1} \mathrm{H}$-NMR spectra of the SLS before and after grafting with AA. A comparison between Fig. 6(a) and (b) shows a carboxyl (carbonyl) characteristic peak near $\delta=6.32-6.14$, 5.79 after the grafting reaction of SLS and AA, indicating that $\mathrm{GC}_{\mathrm{S}-\mathrm{A}}$ is successfully synthesized. Moreover, the results are consistent with the FTIR analysis. Meanwhile, the integral areas of hydrogen-related peaks in the ${ }^{1} \mathrm{H}-\mathrm{NMR}$ spectra suggest that the carboxyl (carbonyl) amount in the graft copolymer is significantly higher after the grafting reaction. This is because the double bond carboxylic acid in AA is introduced to the copolymer as a monomer, providing carboxyl for the copolymer molecule and crosslink points for the reaction. The carboxyl can react with the hydroxyl in the molecule chain or SLS, increasing

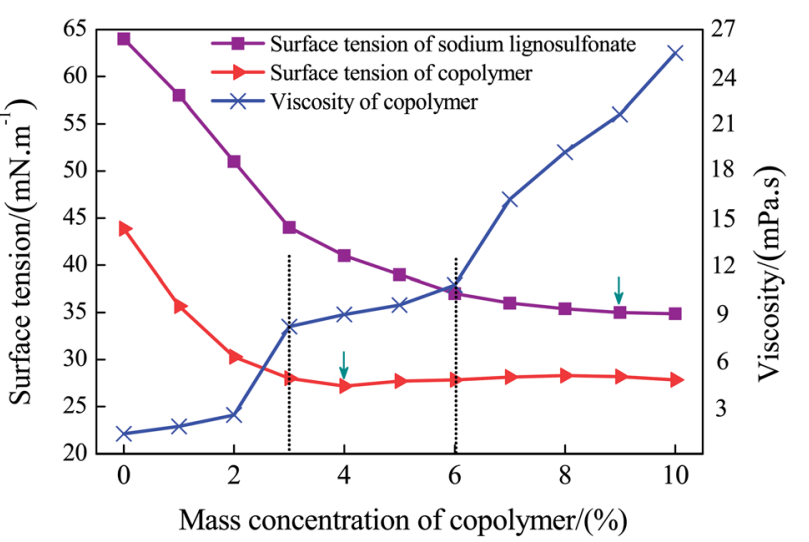

Fig. 7 The viscosity and surface tension of the copolymer solution as a function of the mass fraction. 


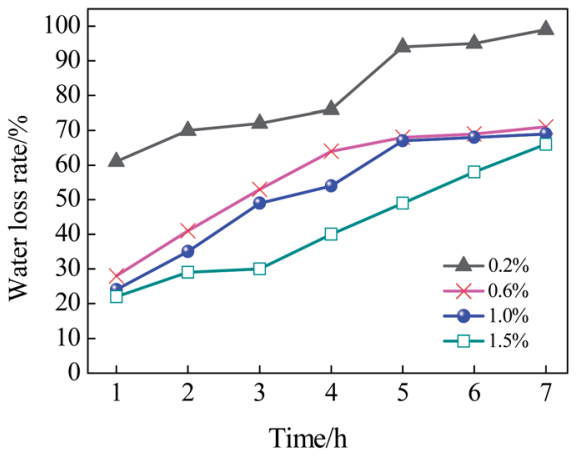

(a) Shenmu lignite coal (HM)

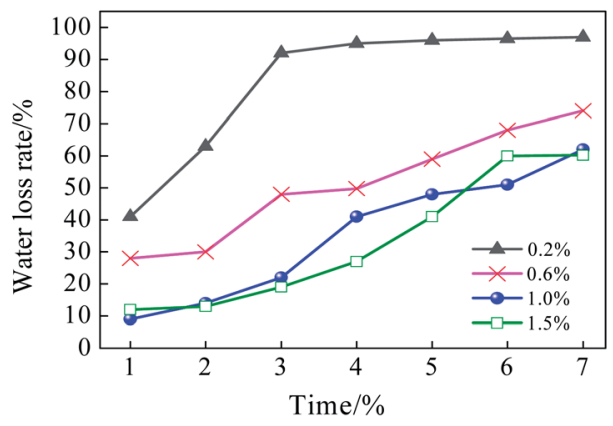

(c) Huipodi $1 / 3$ coking coal (1/3JM)

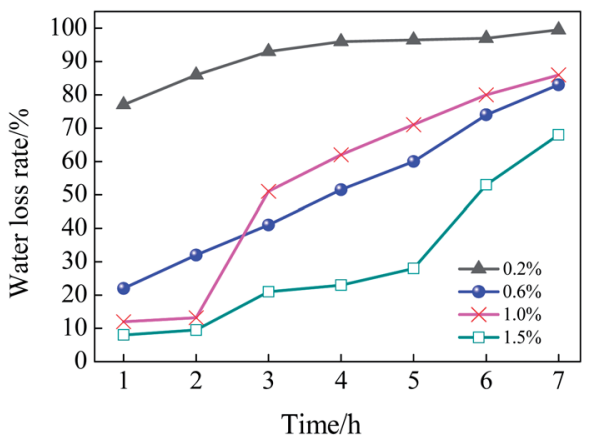

(e) Shiquan meager-mean coal (PSM)

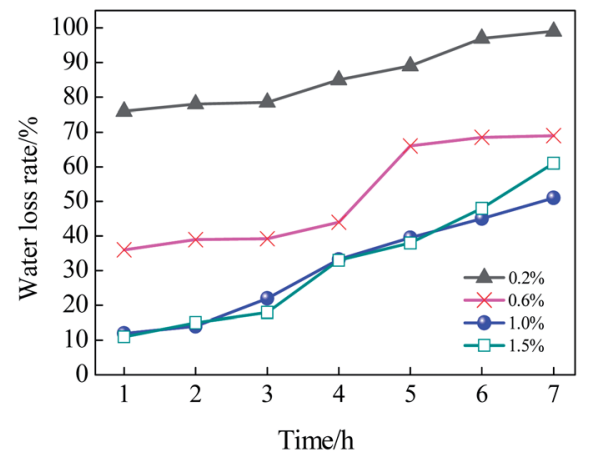

(b) Hebi long flame coal (CY)

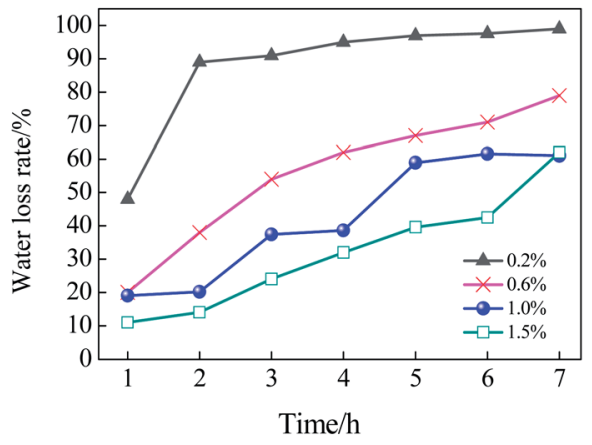

(d) Jiangzhuang fat coal (FM)

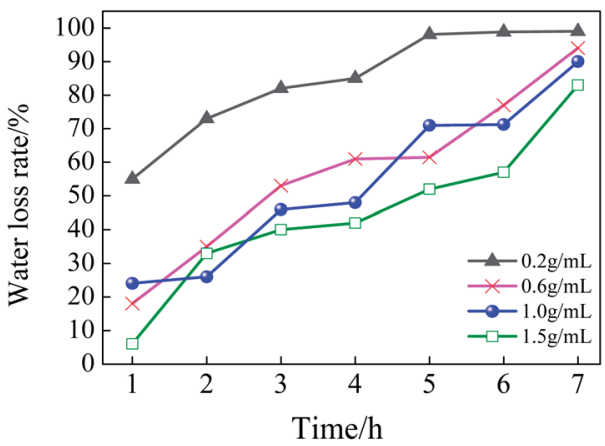

(f) Tongzi anthracite coal (WY)

Fig. 8 The influence of the glycerin concentration on the water retention performance of coal powders.

the viscosity of the copolymer. Thus, $\mathrm{GC}_{\mathrm{S}-\mathrm{A}}$ can bond easily to a coal particle and enhance the capture rate of coal dust particles by the dust depressor.

\section{The surface tension and viscosity analysis}

The wetting of the dust particles can be enhanced by modifying the surface tension between the liquid and solid-liquid. Meanwhile, the appropriate viscosity of the solution can increase its cohesive force on the coal powders. Thus, both the surface tension and viscosity are of great importance. In this paper, $\mathrm{GC}_{\mathrm{S}-\mathrm{A}}$ solutions with various mass fractions were prepared, and the viscosity and surface tension were measured under the same conditions. Having analyzed the experimental results, the viscosity and surface tension of the copolymer solution as a function of the mass fraction are shown in Fig. 7.

According to Fig. 7, at a room temperature of $25{ }^{\circ} \mathrm{C}$ and with an increase of the solution mass fraction, the surface tension of SLS and $\mathrm{GC}_{\mathrm{S}-\mathrm{A}}$ demonstrate a sharp initial decrease, followed by a mild decrease until a constant value is achieved. Before the grafting reaction, the surface tension of the SLS reaches a minimum value of $38.5 \pm 0.5 \mathrm{mN} \mathrm{m}^{-1}$ with a mass fraction of $8-9 \%$. After the grafting reaction, the surface tension of the $\mathrm{GC}_{\mathrm{S}-\mathrm{A}}$ reaches a minimum value of $26.7 \pm 0.5 \mathrm{mN} \mathrm{m}^{-1}$ with a mass fraction of $3-4 \%$. Thus, the surface tension of the SLS solution is greatly reduced after grafting with AA to form $\mathrm{GC}_{\mathrm{S}-\mathrm{A}}$. Meanwhile, the variation trend of the viscosity as a function of 


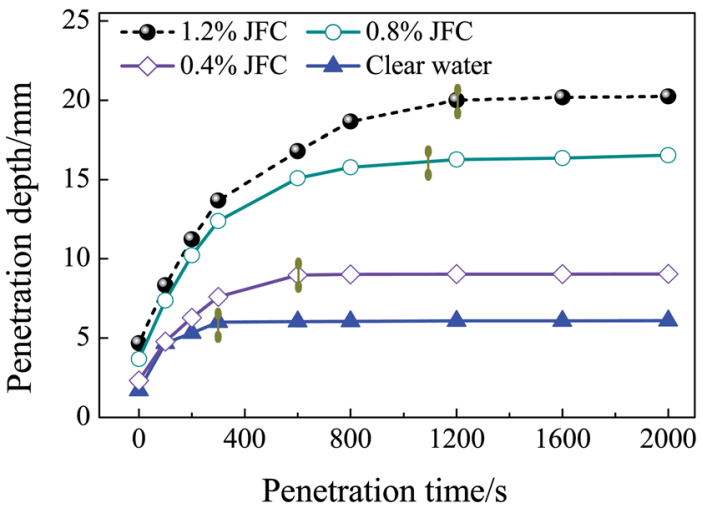

Fig. 9 The penetration depth as a function of time.

various mass fractions indicates that the viscosity increases significantly with the increase of the mass fraction. Nevertheless, a high viscosity may cause difficulties in the spraying process. Thus, further considerations should be taken into account to determine the best mass concentration range. The variation trend of the surface tension and viscosity of the $\mathrm{GC}_{\mathrm{S}-\mathrm{A}}$ solution suggest that both the surface tension and viscosity are within a relatively good region, as the mass fraction of the solution is $3-6 \%$. Therefore, the preliminarily optimized mass fraction of the main material $\mathrm{GC}_{\mathrm{S}-\mathrm{A}}$ should be $3-6 \%$.

\section{The influence of glycerin on the water retention of coal powders}

The glycerin additive can affect the water retention of coal powders. In order to determine the proper mass fraction for glycerin, six coal samples were selected based on their coalification degrees, and the water retention performance was measured with a glycerin mass fraction of $0.2 \%, 0.6 \%, 1.0 \%$, and $1.5 \%$. The results are shown in Fig. 8(a)-(e).

As shown in Fig. 8(a)-(e), glycerin has an apparent effect on the water retention performance of the coal powders. As the mass fraction of glycerin increases, the water retention is significantly enhanced. Nevertheless, as the mass fraction increases from $1.0 \%$ to $1.5 \%$, the water retention ceases to further improve. As an auxiliary for a dust depressor, glycerin has a good moisture absorbance and water retention. However, an overdose of glycerin can limit the stretching of the molecule chain, reducing the ability to store water. In addition, as the coalification degree increases, the effect of glycerin on the water retention performance is reduced. As shown in Fig. 8(a) (HM sample) and 8(b) (CY sample), as the mass fraction of the spraying glycerin reaches $0.6-1.5 \%$, the maximum water loss rate is below 70\%. In Fig. 8(f)

Table 3 The levels of the various factors in the orthogonal experiment

\begin{tabular}{llll}
\hline Factor & $A$ & $B$ & $C$ \\
\hline 1 & $3 \%$ & $0.6 \%$ & $0.4 \%$ \\
2 & $4 \%$ & $0.8 \%$ & $0.5 \%$ \\
3 & $5 \%$ & $0.9 \%$ & $0.6 \%$ \\
4 & $6 \%$ & $1.0 \%$ & $0.8 \%$
\end{tabular}

Table 4 The results of the orthogonal experiment

\begin{tabular}{|c|c|c|c|c|}
\hline No. & $A \%$ & $B \%$ & $C \%$ & $\begin{array}{l}\text { Contact } \\
\text { angle }{ }^{\circ}\end{array}$ \\
\hline 1 & 3 & 0.6 & 0.4 & 33.1 \\
\hline 2 & 3 & 0.8 & 0.5 & 28.2 \\
\hline 3 & 3 & 0.9 & 0.6 & 26.1 \\
\hline 4 & 3 & 1 & 0.8 & 23.8 \\
\hline 5 & 4 & 0.6 & 0.5 & 28.7 \\
\hline 6 & 4 & 0.8 & 0.4 & 26.4 \\
\hline 7 & 4 & 0.9 & 0.8 & 24.2 \\
\hline 8 & 4 & 1 & 0.6 & 20 \\
\hline 9 & 5 & 0.6 & 0.6 & 26.8 \\
\hline 10 & 5 & 0.8 & 0.8 & 24.7 \\
\hline 11 & 5 & 0.9 & 0.4 & 22.6 \\
\hline 12 & 5 & 1 & 0.5 & 33.5 \\
\hline 13 & 6 & 0.6 & 0.8 & 24.5 \\
\hline 14 & 6 & 0.8 & 0.6 & 22.9 \\
\hline 15 & 6 & 0.9 & 0.5 & 21.5 \\
\hline 16 & 6 & 1 & 0.4 & 28.2 \\
\hline $\mathrm{K}_{1}$ & 27.8 & 28.28 & 27.58 & \\
\hline $\mathrm{K}_{2}$ & 24.83 & 25.55 & 27.98 & \\
\hline $\mathrm{K}_{3}$ & 26.9 & 23.6 & 23.95 & $B C A$ \\
\hline $\mathrm{K}_{4}$ & 24.28 & 26.38 & 24.3 & \\
\hline $\mathrm{R}$ & 3.52 & 4.68 & 4.03 & \\
\hline
\end{tabular}

(WY sample), the water loss rate at 7 hours is above $90 \%$. This is because as the coalification degree increases, the wetting becomes poor, leading to decreased water retention.

Overall, taking into account both water retention performance and ecological factors, the preliminary mass fraction of glycerin should be between $0.6 \%$ and $1.0 \%$.

\section{An analysis of the penetration performance}

Fig. 9 reflects the penetration depth as a function of time in the penetration test. According to Fig. 9, compared to the JFC penetrant, the penetration depth of pure water is significantly smaller. After a penetration time of 1200, 1100, and $600 \mathrm{~s}$, JFC solutions with a mass fraction of $0.4 \%, 0.8 \%$ and $1.0 \%$ become stable. The penetration depth of pure water becomes stable at $300 \mathrm{~s}$. Finally at $2000 \mathrm{~s}$, the penetration depth of JFC solutions with a mass fraction of $0.4 \%, 0.8 \%$ and $1.0 \%$ is $3.32,2.24$, and 1.22 times the depth for pure water. Thus, the JFC possesses an apparent enhanced penetration performance. Moreover, the JFC solution with a mass fraction of $1.8 \%$ shows little difference when compared to the $1.0 \%$ solution. Therefore, taking into account ecological factors, the preliminary mass fraction of the penetrant should be $0.4 \%$ to $0.8 \%$.

Table 5 The formulas of the four dust depressors preliminarily selected by the orthogonal experiment

\begin{tabular}{ll}
\hline Formula & Component \\
\hline 1 & $6 \% A+0.9 \% B+0.6 \% C$ \\
2 & $6 \% A+0.9 \% B+0.8 \% C$ \\
3 & $4 \% A+0.9 \% B+0.6 \% C$ \\
4 & $4 \% A+0.9 \% B+0.8 \% C$
\end{tabular}


Table 6 The average dust mass concentration at each point of the cross sections at various distances from the spray field

\begin{tabular}{|c|c|c|c|c|c|c|c|c|c|c|c|c|}
\hline Distance to spray field $/ \mathrm{m}$ & \multicolumn{2}{|c|}{$\begin{array}{l}\text { No dust } \\
\text { reduction } \\
\text { method }\end{array}$} & \multicolumn{2}{|c|}{ Clear water } & \multicolumn{2}{|c|}{ Formula 1} & \multicolumn{2}{|c|}{ Formula 2} & \multicolumn{2}{|c|}{ Formula 3} & \multicolumn{2}{|c|}{ Formula 4} \\
\hline 2 & 812.6 & 426.1 & 266.7 & 127 & 76.4 & 51.1 & 97.5 & 75.8 & 117.8 & 78.4 & 113 & 60.5 \\
\hline 3 & 729.5 & 364.2 & 215.2 & 139.5 & 70.5 & 47.2 & 140.1 & 76.1 & 134.2 & 83.4 & 106.5 & 70.7 \\
\hline
\end{tabular}

\section{An analysis of the orthogonal experimental results}

In order to select the optimum formula for a dust depressor, an orthogonal experiment was designed, as shown in Table 3. A max-min difference analysis of the contact angle was conducted, and the results are shown in Table 4.

$\mathrm{K}_{1}, \mathrm{~K}_{2}, \mathrm{~K}_{3}$, and $\mathrm{K}_{4}$ reflect the influence of various factors on the experimental index. A smaller contact angle between the dust depressor and coal powder is generally preferred. According to the results in Tables 3 and $4, A_{4}, A_{2}, B_{3}, C_{3}$, and $C_{4}$ are the optimum levels for each factor. A comparison of $R$ values gives the following: $R_{\mathrm{B}}>R_{\mathrm{C}}>R_{\mathrm{A}}$. Thus, the influence of the factors on the contact angle ranks as $B>C>A$.

Overall, the optimum combinations of the three factors are $A_{4} B_{3} C_{3}, A_{4} B_{3} C_{4}, A_{2} B_{3} C_{3}$, and $A_{2} B_{3} C_{4}$. The four formulas of dust depressor determined by the orthogonal experiment are shown in Table 5.

\section{An analysis of the dust reduction rate}

The dust control performance of the four dust depressors selected by the orthogonal experiment were tested in a large-scale mine spraying test box in the key state laboratories at Shandong University of Science and Technology. At a spraying pressure of $8 \mathrm{MPa}$, the mass concentrations of the total dust and respirable dust were measured for each formula. Four different cross sections located at $2,3,4$, and $5 \mathrm{~m}$ from the spray field were selected with 7 measurement points at each cross section. The average mass concentrations of the total dust and respirable dust were measured at each point. The results are shown in Table 6 . Using the data in Table 6, the average dust reduction rates of the total dust and respirable dust for each formula were calculated, and the results are summarized in a line chart (Fig. 10).

According to Table 6 and Fig. 10, compared to water spraying dust suppression techniques, the dust reduction rates of the four chemical dust depressors in this paper are significantly higher.

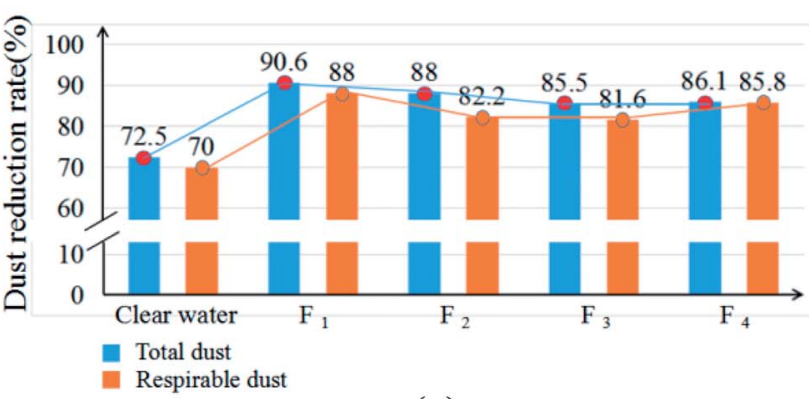

(a)

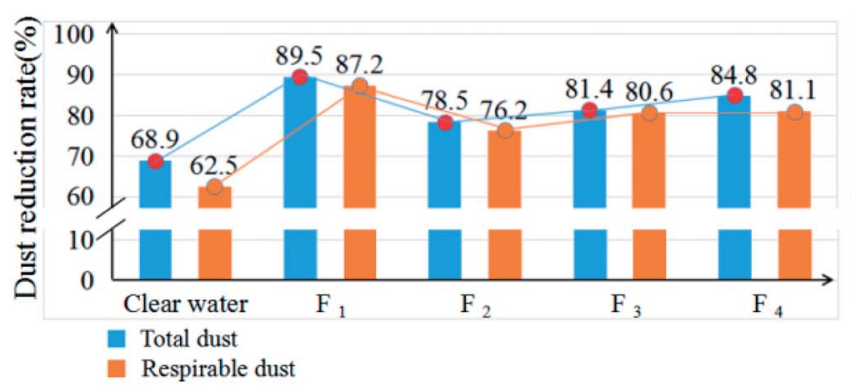

(c)

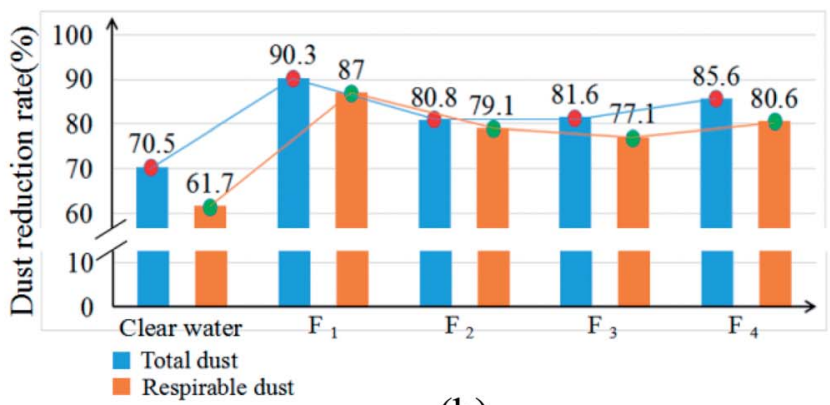

(b)

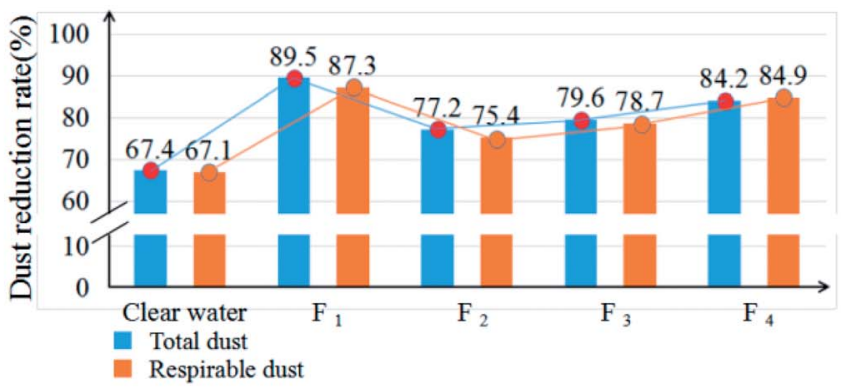

(d)

Fig. 10 The average dust reduction rate of the total dust and respirable dust at the cross sections at different distances from the spray field. 


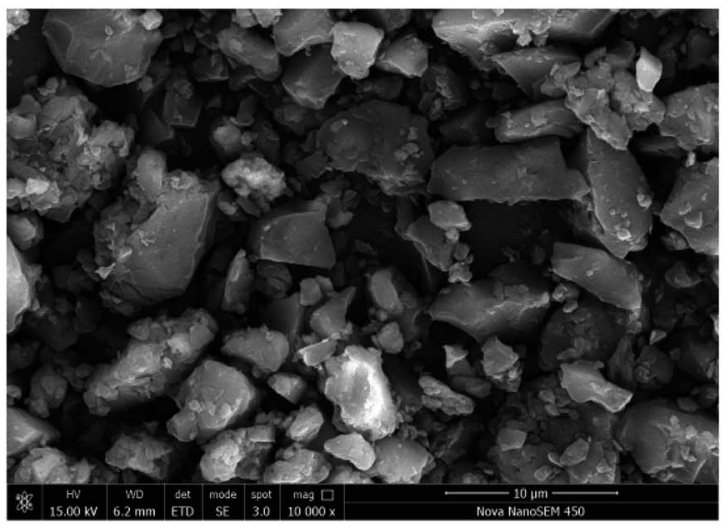

(a)

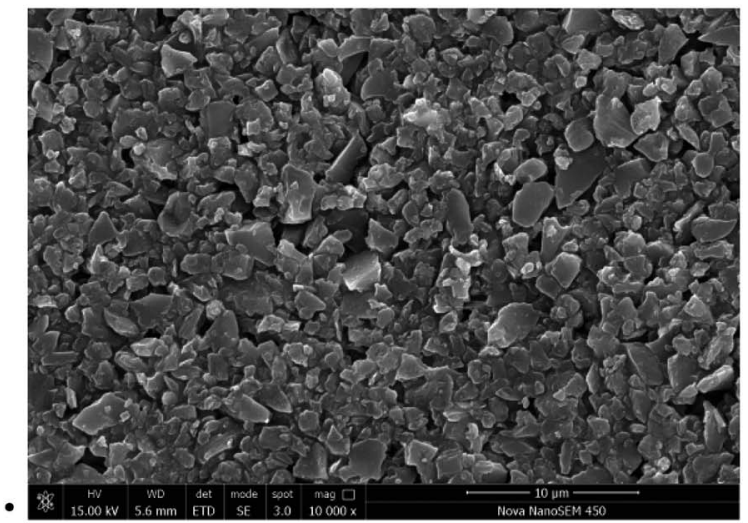

(b)

Fig. 11 SEM photo of coal powder solidifying effect: (a) dry coal dust under $10000 \times$ SEM; (b) coal dust after spraying dust suppressant under $10000 \times$ SEM.

After using the spraying dust depressor of formula 1, the average mass concentrations of the total dust and respirable dust at 2, 3, 4, and $5 \mathrm{~m}$ from the spray field decrease from 812.6 and 426.1 to 76.4 and 51.1, respectively. The average dust reduction rates of the total dust and respirable dust at each point increase from $72.5 \%$ and $70 \%$ to $90.6 \%$ and $88 \%$, respectively. Thus, the dust reduction performance of formula 1 is apparently higher than the other three formulas. Therefore, the highly efficient dust depressor in this paper reduces the dust mass concentration in the test box significantly, thereby improving the environmental quality.

\section{Analysis of SEM results}

In order to investigate the effect of the new dust suppressant on the agglomeration and hardening of the coal powder, the present study uses high-resolution SEM to examine and compare the surface morphology of the dry coal powder without the spray of dust suppressant as well as the coal powder applied with the newly developed hybrid dust suppressant. The SEM images are shown in Fig. 11. Specifically, Fig. 11(a) depicts the surface morphology of the desiccated coal powder under $10000 \times$ SEM without the application of dust suppressant. It can be found that the spacing between coal dust particles is relatively large, and no agglomeration pattern is observed. This is mainly due to the fact that the surface of the coal dust contains large amount of hydrophobic groups, and there lacks cementing effect between particles. Therefore, the distribution of particles is scattered, and consequently the coal dust has a strong tendency to undergo dispersion driven by wind, leading to severe pollution. Fig. 11(b) shows the $10000 \times$ SEM image of the coal power undergoing the treatment of the new hybrid dust suppressant followed by desiccation. It is evident that the surface of coal powder is relatively smooth, and the coal dust particles are tightly connected with small spacing. This is due to the fact that the dust suppressant coats the coal dust surface with a hardened film. The film gives rise to a decent cementing effect between dust particles, rendering the coal dust particles a strong tendency to experience agglomeration. The reentrainment of coal dust is thereby suppressed.

\section{An analysis of coal quality}

According to the general regulation of People's Republic of China national standard coal analysis and test method, the coal dust samples before and after spraying the dust suppressant were analyzed. Four representative coal samples from different regions were selected for determination depending on the degree of coalification. They are long flame coal (CY) from Shanxi Daliuta coal mine, 1/3 coking coal (1/3 JM) from Shanxi Huipodi coal mine, gas-fat coal (FM) from Shandong

Table 7 Results of coal dust before and after spray dust suppressant developed in this paper ${ }^{a}$

\begin{tabular}{|c|c|c|c|c|c|c|c|}
\hline \multicolumn{2}{|c|}{ Coal sample } & $\frac{\text { Total moisture }}{M_{\mathrm{t}}}$ & $\frac{\text { Analytical water }}{M_{\mathrm{ad}}}$ & $\frac{\text { Ash content }}{A_{\mathrm{d}}}$ & $\frac{\text { Volatile matter }}{V_{\mathrm{d}}}$ & $\frac{\text { Total sulfur }}{S_{\mathrm{t}, \mathrm{d}}}$ & $\frac{\text { Calorific value }}{Q_{\mathrm{gr}, \mathrm{d}}\left(\mathrm{MJ} \mathrm{kg}^{-1}\right)}$ \\
\hline \multirow[t]{2}{*}{ CY } & $1^{\#}$ & 19.41 & 5.56 & 6.22 & 33.25 & 0.48 & 25.84 \\
\hline & $2^{\#}$ & 20.79 & 3.45 & 6.31 & 33.74 & 0.476 & 25.68 \\
\hline \multirow[t]{2}{*}{ FM } & $1^{\#}$ & 17.22 & 1.55 & 5.6 & 30.56 & 0.39 & 35.62 \\
\hline & $2^{\#}$ & 19.56 & 1.53 & 5.64 & 30.47 & 0.38 & 34.87 \\
\hline \multirow[t]{2}{*}{ WY } & $1^{\#}$ & 14.32 & 2.69 & 7.21 & 9.64 & 0.35 & 40.01 \\
\hline & $2^{\#}$ & 17.3 & 2.7 & 7.18 & 9.39 & 0.33 & 39.55 \\
\hline
\end{tabular}

${ }^{a} 1^{\#}$ and $2^{\#}$ respectively represent the samples of raw coal and the coal simple after spraying dust suppressant. 
Jiangzhuang coal mine and anthracite coal (WY) from Guizhou Tongzi coal mine. Table 7 is the analysis results of coal dust before and after spray dust suppressant developed in this paper.

The comparison data in Table 7 indicate that after spraying the dust suppressant, the total moisture content of the coal sample increases, this is because the dust suppressant is an aqueous solution, which brings the total moisture content of the surface coal after spraying the dust suppressant; similarly, the coal total moisture also increased coal calorific value slightly causes. The reduced calorific value is all less than $0.1 \%$, the effects are almost negligible. In addition, the whole water section of the coal surface will gradually evaporate during transportation, the resulting increase in moisture is also eliminated. Futhermore, spraying dust suppressant has no influence on ash content, volatile content and total sulfur content of coal. Therefore, the new hybrid dust suppressant developed in this paper will not affect the quality of coal.

\section{Conclusions}

In this paper, a sodium lignosulfonate-acrylic acid graft copolymer was synthesized using low-cost polymer sodium lignosulfonate. The optimized reaction condition determined by the orthogonal experiment was as follows: a reaction temperature of $60{ }^{\circ} \mathrm{C}$, feed ratio $m_{\mathrm{SLS}-\mathrm{AA}}$ of $1: 3$, and $\mathrm{FeSO}_{4}$ $\cdot 7 \mathrm{H}_{2} \mathrm{O}$ content of $2.5 \%$. The FTIR spectrum confirms the introduction of AA into SLS, the ${ }^{1} \mathrm{H}-\mathrm{NMR}$ spectrum shows that the variation of the group peak position for the graft copolymer is consistent with the FTIR results. Meanwhile, the carboxyl group on the copolymer has a crosslinking structure with the molecular chain or the hydroxyl group on SLS, which can increase the viscosity of the polymer. Four kinds of dust reducing agents were selected through water conservation experiment and permeability test, finally, the optimum formula was determined by the spray dust reduction experiment. From an analysis of the experimental results, the new dust depressor developed in this paper has no effect on the quality of the coal. In summary, the novel, ecological, highly efficient dust depressor developed in this paper is environmentally-friendly and easily degradable, with a significantly enhanced dust reduction performance.

\section{Conflicts of interest}

There are no conflicts to declare.

\section{Acknowledgements}

This work has been funded by the China Postdoctoral Science Foundation (No. 2017T100503 and 2015M570601), the Focus on Research and Development Plan in Shandong Province (No. 2017GSF20111), the National Key R\&D Program of China (No. 2017YFC0805201), and the National Natural Science Foundation of China (No. 51404147).

\section{Reference}

1 R. J. Blanka Binkova, M. Dostal, M. M. Dostalova, H. Libalova, A. Milcova, P. R. Hu Jin Jr, A. Rossnerova, J. Schmuczerova, V. Svecova, J. Topinka and H. Votavova, Health impact of air pollution to children, Int. J. Hyg. Environ. Health, 2013, 216, 533-540.

2 W. Nie, Y. H. Liu, H. Wang, W. L. Wei, H. T. Peng, P. Cai, Y. Hua and H. Jin, The development and testing of a novel external-spraying injection deducting device for the heading machine in a fully-mechanized excavation face, Process Saf. Environ. Prot., 2017, 109, 716-731.

3 W. Nie, W. L. Wei, X. Ma, Y. H. Liu, H. T. Peng and Q. Liu, The effects of ventilation parameters on the migration behaviors of head-on dusts in the heading face, Tunnelling and Underground Space Technology, 2017, 70, 400-408.

4 H. Wang, W. Nie, W. M. Cheng, Q. Liu and H. Jin, Effects of air volume ratio parameters on air curtain dust suppression in a rock tunnel's fully-mechanized working face, $A d v$. Powder Technol., 2018, 29, 230-244.

5 W. Nie, X. Ma, W. M. Cheng, Y. H. Liu, L. Xin, H. T. Peng and W. L. Wei, A novel spraying/negative-pressure secondary dust suppression device used in fully mechanized mining face, Process Saf. Environ. Prot., 2016, 103, 126-135.

6 Q. Liu, W. Nie, Y. Hua, H. T. Peng and Z. Q. Liu, The effects of the installation position of a multi-radial swirling air-curtain generator on dust diffusion and pollution rules in a fullymechanized excavation face: A case study, Powder Technol., 2018, 329, 371-385.

7 H. T. Wang, D. M. Wang, G. Chen and W. X. Ren, Preparation and application of the high-performance foam for suppressing dust, China Mining Magazine, 2012, 21(7), 114116.

$8 \mathrm{~J}$. Kim, Effect of coal type on wetting by solutions of Nonionic surfactant, International Mining and Minerals, 1999, 2(14), 38-41.

9 H. M. Wang and C. Wu, Development of a dust suppression and high strength water absorption resin for pavement, $J$. Cent. South Univ. Technol., 1995, 26(3), 319-323.

10 C. F. Du, Z. A. Jiang, Y. Xu, H. P. Lv and X. J. Yao, Industrial Test on Depression of Flying Dust at Open Coal Yard by Cohesive Dust Depressor, Metal Mine, 2005, (3), 55-57.

11 M. A. Medeiros, C. M. M. Leite and R. M. Lago, Use of glycerol by-product of biodiesel to produce an efficient dust suppressant, Chem. Eng. J., 2012, 180, 364-369.

12 S. Y. Cheng and Y. H. Hao, Synthesis of coal dust depressor by waste paper and its application, Chin. J. Environ. Eng., 2013, 7(9), 9.

13 C. Wu, Chemical Suppression of Dust, Central South University Press, Changsha, 2003. pp. 3-13.

14 Y. H. Liu, W. Nie, H. Jin, H. Ma, Y. Hua, P. Cai and W. L. Wei, Solidifying dust suppressant based on modified chitosan and experimental study on its dust suppression performance, Adsorpt. Sci. Technol., 2018, 36(1-2), 640-654.

15 C. Hao, J. J. Wang, Q. Cheng, Y. Bai, X. H. Wang and Y. L. Yang, Anionic surfactants-assisted solution-phase 
synthesis of $\mathrm{ZnO}$ with improved photocatalytic performance, J. Photochem. Photobiol., A, 2017, 332, 84-390.

16 X. H. Wang, Y. Y. Wang, H. Q. Hou, J. J. Wang and C. Hao, Ultrasonic Method to Synthesize Glucan-g-poly(acrylic acid)/Sodium Lignosulfonate Hydrogels and Studies of Their Adsorption of $\mathrm{Cu}^{2+}$ from Aqueous Solution, ACS Sustainable Chem. Eng., 2017, 5, 6438-6446.

17 X. H. Wang, Z. L. Zhou, X. W. Guo, Q. He, C. Hao and C. W. Ge, Ultrasonic-assisted synthesis of sodium lignosulfonate-grafted poly (acrylic acid-co-poly (vinyl pyrrolidone)) hydrogel for drug delivery, RSC Adv., 2016, 6(42), 35550-35558.

18 H. H. Xia, Y. X. Zhang, C. L. Chen, W. L. Wu, K. Yao and J. Zhang, Ozone-Mediated Functionalization of MultiWalled Carbon Nanotubes and Their Activities for Oxygen Reduction Reaction, J. Mater. Sci. Technol., 2016, 32(6), 533-538.

19 C. Hao, Y. M. Xu, M. J. Bao, X. H. Wang, H. L. Zhang and T. H. Li, Hydrothermal synthesis of sphere-like BiOCl using sodium lignosulphonate as surfactant and its application in visible light photocatalytic degradation of rhodamine B, J. Mater. Sci.: Mater. Electron., 2017, 28, 3119-3127.

20 X. H. Wang, F. S. Wu, Y. W. Duan, Y. Y. Wang, C. Hao and C. W. Ge, Lignin-assisted solid-phase synthesis of nano$\mathrm{CuO}$ for a photocatalyst with excellent catalytic activity and high performance supercapacitor electrodes, RSC Adv., 2016, 6, 65644.

21 Y. Zheng, Preparation of new dust suppressant and its performance, J. Shanghai Inst. Technol., 2014, 14(2), 106-108.

22 H. Quan (Sophia), M. Josiah and Y. Jie, Utilization of the residual glycerol from biodiesel production for renewable energy generation, Renew. Sust. Energ. Rev., 2017, 71, 63-76.
23 C. Hao, Y. R. Shen, Z. Y. Wang, X. H. Wang, F. Feng, C. W. Ge, Y. T. Zhao and K. Wang, Preparation and Characterization of $\mathrm{Fe}_{2} \mathrm{O}_{3}$ Nanoparticles by Solid-Phase Method and Its Hydrogen Peroxide Sensing Properties, ACS Sustainable Chem. Eng., 2016, (4), 1069-1077.

$24 \mathrm{H}$. Zhao, Synthesis and properties research of a new sand fixing agent lignin sulfonate graft urea-formaldehyde resin, MPhil. thesis, Beijing University of Chemical Technology, Beijing, 2015.

25 Y. Chen, F. J. Wang, D. R. Ran, Y. W. Guo, Y. C. Ye, Y. X. Wang and H. M. Tan, Preparation of a C6 Quaternary Ammonium Chitosan Derivative Through a Chitosan Schiff Base with Click Chemistry, J. Appl. Polym. Sci., 2013, 129, 3185.

26 X. D. Zhao, Discussion on national standard of GB/T 4822008. Sampling of coal seams, Coal Quality Technology, 2011, (02), 22-24.

27 X. Zhou, J. Z. Yang, Q. Gao and G. H. Qu, Study on heat hardening mechanism of starch composite binder for sand mold (core) by IR spectra, J. Mater. Sci. Technol., 2001, 17(S1), 143-146.

28 Y. Yuan, Preparation and life cycle assessment of environmentfriendly wooden composites based on modified industrial lignins, PhD thesis, Northeast Forestry University, Heilongjiang, 2014, pp. 3-11.

29 W. M. Cheng, X. M. Hu, J. Xie and Y. Y. Zhao, An intelligent gel designed to control the spontaneous combustion of coal: Fire prevention and extinguishing properties, Fuel, 2017, 210, 826-835.

30 J. J. Liu, X. Q. Qiu and X. S. Tian, Numerical analysis of the flame structural characteristics of light oil burner of different environmental conditions, J. Shandong Univ. Sci. Technol., Nat. Sci., 2018, 37(2), 80-87. 